\title{
Feedforward and Feedback DC Motor Control Methods of Control Systems
}

\author{
Aaron Don M. Africa, Darlene Alyssa P. Abaluna, Ara Jyllian A. Abello, Joaquin Miguel B. Lalusin \\ Department of Electronics and Communications Engineering \\ De La Salle University, Manila \\ 2401 Taft Ave., Malate, Manila 1004, \\ Philippines, aaron.africa@dlsu.edu.ph
}

\begin{abstract}
DC motors are the most popular transducers used in the industry. Their versatility allows them to be used and configured in many different varieties, therefore, it is important to know which method to use for controlling them as there are currently many designs for different DC motors and different applications. This paper focuses on comparing the feedforward and feedback motor control methods. The DC motor design that the paper will consider is a voltage-controlled armature driven DC motor. The group will use MATLAB to simulate the two methods and will implement them to the motor. In addition to that, setpoint command tracking will also be a parameter to be considered in determining the performance of the two methods. Furthermore, a comparison of their performance against each other will be done by introducing a load disturbance in the armature-controlled DC motor in order to determine their sensitivity to possible noise in the system.
\end{abstract}

Key words: DC motor, feedforward, feedback, root locus, MATLAB.

\section{INTRODUCTION}

DC motors are transducers that convert electrical energy to mechanical energy, they are currently the most widely used actuators in its class [1]. Its applications range from small toys to conveyor belts in manufacturing to robots in automated systems. There are two main components in a DC motor i.e. the stator and the armature, the armature rotates thanks to the magnetic field generated by the stator. Although DC motors can be categorized into different types, they operate similarly at a fundamental level. The first type is called the Brushed DC Motor, this was one of the very first DC motor designs; it uses soft contacts known as "brushes" to make sure that the motor will only rotate in a single direction. Brushless DC Motors was innovated from the original brushed design [2], these differed from the Brushed DC Motors because they did not use commutators due to the fact that their brushes would wear down with regular use. Brushless DC Motors instead use servomechanisms which can sense the rotor angle and then adjust accordingly, they are more durable than the brushes present in the previous design [3,4]. Although Brushless DC Motors are favored over Brushed DC Motors there are still many applications that use Brushed DC Motors and from these applications came two more variants of the Brushed DC Motors, these are the Shunt and Series DC Motors. DC Shunt Motors are mostly used in situations where a constant torque is needed, the motors have their field windings in parallel with the armature of the motor [5]. Whereas, Series DC Motors have their field windings in series with the armature [6]; this makes the motor output higher speed and higher initial torque. Due to the variety of their designs and versatility of their applications, it is important to have some form of control over these motors; especially in high precision applications such as robotics.

\section{BACKGROUND OF THE STUDY}

DC series motors are very useful actuators for moving and controlling a system or a mechanism [7]. These devices are used to initiate a torque for smaller or bigger machines. The DC series motors have higher torque than other motors and this is the reason why the DC series motors are widely used for traction applications. Another type of motor is known as the universal motor due to its applicability in $\mathrm{AC}$ or DC supply. It is the series-wound motors. These examples develop more power compared to the Shunt DC motor with the same construction size. Although these motors are useful, these can still have disadvantages. One of the disadvantages of DC motors is speed control and regulation. There is not much control when it comes to DC motors. It is also a necessity for DC series motors to have an initial load before starting as it will not be efficient if there is no load in the initial stage. For the application, these motors are commonly used in traction applications such as locomotives and trolley cars because these systems demand higher torques. These motors are also used in cranes and conveyor belts and systems where high initial torque is required. On the other hand, DC Shunt motors are used in applications where speed control is important, for example, is the rolling mill. Lathe machines are also great examples of this type of motor where a constant 
speed is highly required. These motors can also be found in pumps, blowers and fans. With this in mind we can observe that some of the advantages of DC shunt motors are the use in heavy industrial applications because in these cases, torque and a wide speed range are needed. Shunt-wound motor can run at a predetermined speed. Even though these have a wide range of applications, there are still disadvantages with using such devices, one being expensive, unable to be used in operations where variable speed is needed.

\section{STATEMENT OF THE PROBLEM}

In this paper, feedforward and feedback will have their own disadvantages that will hinder an efficient output and practicality. In the industry, every aspect of a system must work in harmony with the whole system to ensure that the desired output will be met. While feedforward will only compensate or will only predict the output as it does not measure output, this is not ideal in many applications. This control system needs to be "guided" in such a way that computations are done on-line. This control also will not correct itself and will not check the adjustments worked in the process. With feedback control, the system will only react to the process error, which means that it will not have a preventive measure as it will not predict errors in the system. In this paper, there is also a load disturbance in the DC control method. With this in mind, it is essential to study the difference between feedback and feedforward or if a system with both control systems utilized will be most efficient.

\section{SIGNIFICANCE OF THE STUDIES}

It is important to know the key differences between Feedforward vs Feedback DC motor control. Generally, feedforward control is used to reduce the effects of measurable disturbances. It is more of a preventive measure type of application while feedback will tend to compensate for the inaccuracies a system can have, or a process will have in the future. A feedback system will also compensate for measurement errors and disturbances that were not obtained. Figure 1 shows the Comparison of feedforward and feedback control systems.

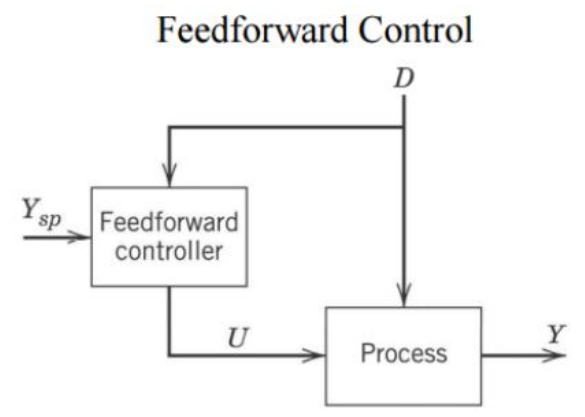

\section{Feedback Control}

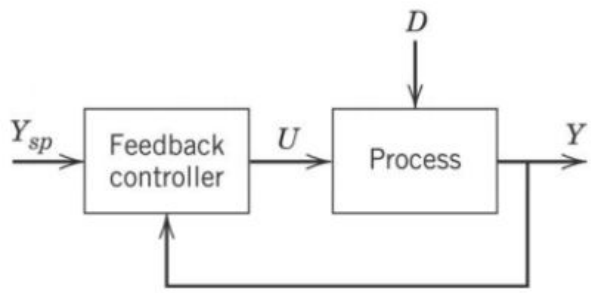

Figure 1: Comparison of feedforward and feedback control systems

Feedforward will have a few disadvantages such as that the disturbance variables must be measured while connected to another computer or network to ensure accuracy. In many applications and systems, this is inefficient. Another disadvantage is the need to know how such a system will respond with changes in both disturbances and manipulated variables. With these in mind, an efficient system will make use of a combination of feedforward and a feedback control system. Such a system will be efficient because the feedforward control is used to reduce the effects of the measurable disturbances while the feedback will compensate for the inaccuracies in the process model [8].

\section{DESCRIPTION OF THE SYSTEM}

This system will consider an armature voltage control, where an applied voltage ( $\mathrm{Va}$ ) can control the speed and torque of a DC motor due to its effect on its angular velocity $(\omega)$. The variable $\mathrm{Td}$ will be the simulated load disturbance, $\mathrm{Kt}$ is the motor torque constant, $\mathrm{L}$ and $\mathrm{R}$ is the inductance and resistance respectively, $\mathrm{J}$ is the moment of inertia of the motor in $\mathrm{kg} \bullet \mathrm{m} 2 / \mathrm{s} 2, \mathrm{~Kb}$ is the back electromotive force (emf) constant in $\mathrm{V} / \mathrm{rad} / \mathrm{sec}$, and $\mathrm{Kf}$ is the constant of viscous friction in Nms. Figure 2 shows the block diagram of the DC motor.

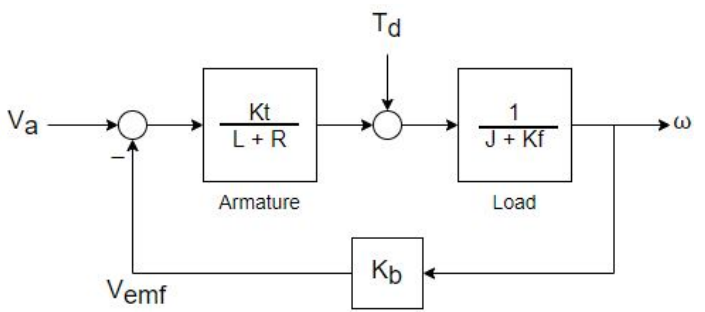

Figure 2:Block diagram of the DC motor

After considering the motor above, two different motor control techniques shall be implemented to determine which of the two can perform better.

\subsection{Feedforward DC Motor Control}

The design of the feedforward control is shown below in Figure 3 where, $\mathrm{G}$ is the feedforward gain, and $\square \mathrm{i}$ is the reference angular velocity which is the target that the DC motor should reach. 


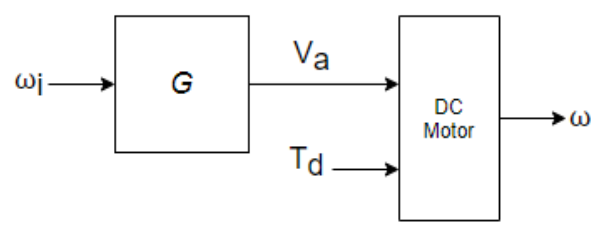

Figure 3: Design of the feedforward control

\subsection{Feedback DC Motor Control}

The design of the feedback control is shown below in Figure 4 where a steady-state error analysis is performed $\mathrm{G}(\mathrm{s})$ and $\mathrm{N}$ is an unknown gain. For the value of $\mathrm{N}$ to be determined the root locus technique will be used.

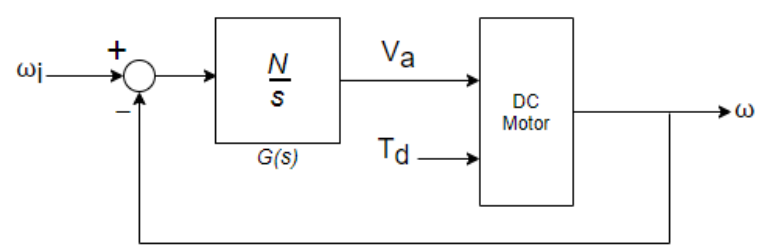

Figure 4: Design of the feedback control

\section{METHODOLOGY}

A. Procedure

1. Open MATLAB.

2. Set the physical parameters of a DC Motor such as the resistance, inductance, torque, angular velocity, and friction.

3. Build the state-space model of the motor using the transfer function model in the Control Systems Toolbox.

4. Plot the angular velocity response with respect to step-change in voltage Va.

5. Initialize the physical constants of a dc motor

6. Set the value of $\mathrm{K}$ to 2.5

7. Simulate the response to a step command w_ref $=1$ with a disturbance $\mathrm{Td}=-0.1 \mathrm{Nm}$ between $\mathrm{t}=5$ and $\mathrm{t}=10$ seconds:

8. Plot using the control system toolbox

9. Enforce zero steady-state error, using $\mathrm{C}(\mathrm{s})=\mathrm{K} / \mathrm{s}$

10. Determine K

11. Use the root locus technique in the control systems toolbox applied to the open-loop $1 / \mathrm{s} *$ transfer(Va->w)

12. Simulate the response to a step command w_ref $=1$ with a disturbance $\mathrm{Td}=-0.1 \mathrm{Nm}$ between $\mathrm{t}=5$ and $\mathrm{t}=10$ seconds:

13. Plot using the control systems toolbox

14. Plot the feedforward and the feedback with root locus in one graph control systems toolbox

\section{REVIEW OF RELATED LITERATURE}

\subsection{Other Motor Control Methods}

Since DC motors are used in high-precision applications, it is imperative that they are controlled with the same level of precision. There are many ways to implement a DC motor control system, the most popular is the Proportional-Integral-Derivative (PID) Controller thanks to its simplicity and reliability $[9,10,11]$. Another popular method for controlling DC motors is by using the Linear Quadratic Regulator (LQR) method, this approach utilizes state space. The main advantage of using LQR is that it can provide a way to calculate the state feedback control systematically. Between the two, however, LQR is proven to perform better with the absence of any disturbances. Furthermore, it indicated more characteristics of better performance such as minimal speed deviation and better response [12]. It is also a low-cost solution and easy to design. Another method for controlling the speed of a DC motor is called the pulse-width modulation (PWM) control [13]. In simple terms, this is a way of controlling the speed of the motor by regulating the amount of voltage applied to its terminals. The voltage is controlled in "pulses" meaning there are only two states that the input voltage is in, which is either on or off; the longer the "on pulse", the faster the motor will run and vice versa. This is because the longer the pulse means more voltage will be applied to the terminals which leads to more current in the armature windings.

There have been many innovations in the field of DC motor control, one design proposed was the use of a Sensorless Control of a brushless DC motor [14]. This design was made due to the fact that traditional means of controlling brushless DC motors are complex and inefficient. The sensorless control approach was successfully implemented and produced very promising results such as a $0.8 \%$ reduction in speed fluctuation and the input power factor was reduced to the minimum allowable limit according to the IEEE standard. Another implementation of a DC motor control system used a fuzzy logic controller-based embedded system [15]. The system used a two input fuzzy controller where the inputs are the error and change in error and the output of the fuzzy controller is the duty cycle. This design was compared against a separately excited motor, it was found that it performed better than the latter. Another design has been compared against the separately excited motors called the Feedforward-Feedback Control [16,17]. This design allows for better setpoint tracking and disturbance rejection. It can do this thanks to a combination of a feedforward and feedback control design. By combining the two designs, the system achieved better stability and better performance. 


\subsection{Speed Control}

The speed of a motor is directly proportional to the supply voltage $[18,19]$, meaning that the motor rotates faster the higher the voltage. It is also inversely proportional to armature voltage drop as well as flux due to field windings [20,21]. Based on this, there are three basic ways to control the speed of a DC motor: by varying the flux, supply voltage, and armature voltage/resistance.

There are ways of varying the previously mentioned parameters to control the speed of the motor. One can use a programmable logic controller (PLC) as a means of controlling the motor speed instead of the usual Thyristors, MOSFETs and IGBTs [22]. The armature circuit is turned on and off using the Pang-pang control method depending on the reference speed and speed control is achieved within a range of $0 \%$ to $100 \%$. While it is effective, motor speed fluctuates during steady state operation.

Another way is to use a state feedback controller [23]. The controller uses a state feedback with a state observer controller incorporating an integrator and is designed using MATLAB/Simulink. The entire system is placed on a dSPACE DSP DS1104 controller board. This method allows the adjustment of the motor speed by controlling the power amplified by the input voltage. After experimenting, it was found that the motor speed can be controlled at the desired speed with a steady-state error of less than $5 \mathrm{rpm}$, meaning that the proposed controller can keep the motor speed at a constant speed which can range from 0 to $3200 \mathrm{rpm}$.

\section{THEORETICAL CONSIDERATIONS}

When designing a DC Motor Control system, it is important to consider the type of motor and its use case $[24,25,26]$. When one has chosen a type of motor and its application, the next thing to consider is which parameter should be controlled i.e. speed, torque, and position or angle of the shaft. Generally, when dealing with higher precision applications where the speed of a DC motor needs to be tightly controlled a system with a feedback loop can help regulate and control the speed of the motor [27]. Whereas, in applications where not much precision is required such as motors with continuous duty cycles, a basic open-loop control system would suffice.

There are three fundamental methods to control DC motors, these methods are what most motor control designs are based on. The first method is controlling the magnetic flux of the motor. The magnetic flux can be controlled by increasing or decreasing the current through the field windings, the current can be controlled by connecting a variable resistor in series with the field winding resistors. Lowering the current will decrease the magnetic flux which will in turn decrease the speed of the motor. The next method is by controlling the voltage of the motor, increasing the voltage input of a DC motor its speed will also increase. A popular voltage control design is the PWM control method [28]. The next method is controlling the armature resistance of the DC motor. By modifying the armature resistance, the armature voltage will also be affected accordingly. Similar to the first method discussed above, a variable resistor is also connected to the armature in series in this approach. In this paper, the design used is that of a voltage control variant wherein changing the input voltage will change the armature voltage which will regulate the speed of the motor.

\section{DATA AND RESULTS}

Figures 5 to 9 shows the responses of the system.

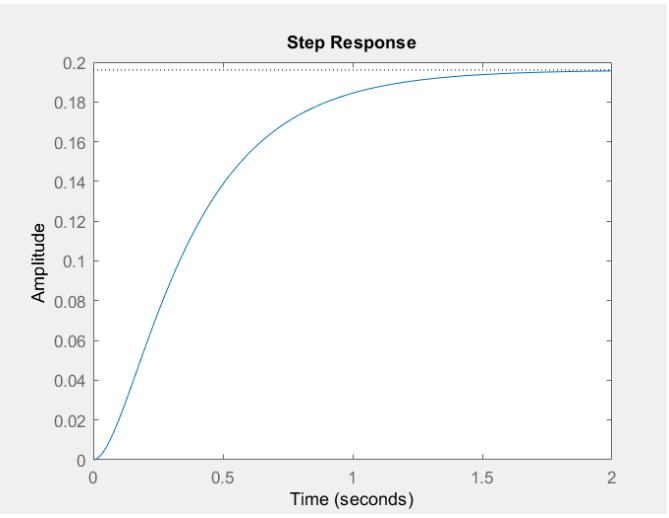

Figure 5:Step Response of a DC Motor

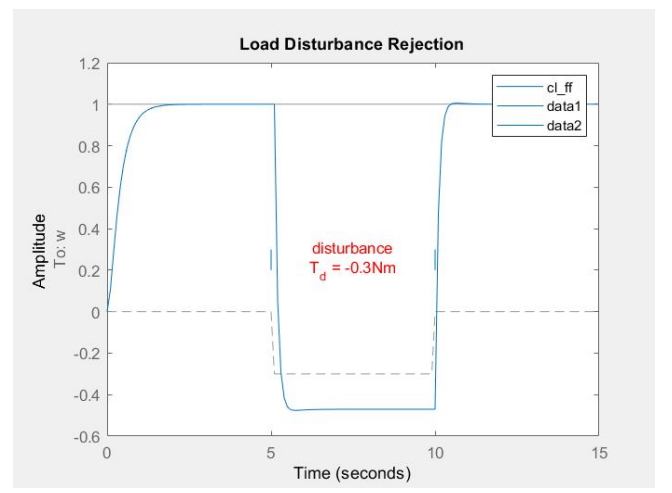

Figure 6:Feedforward Load Disturbance Rejection

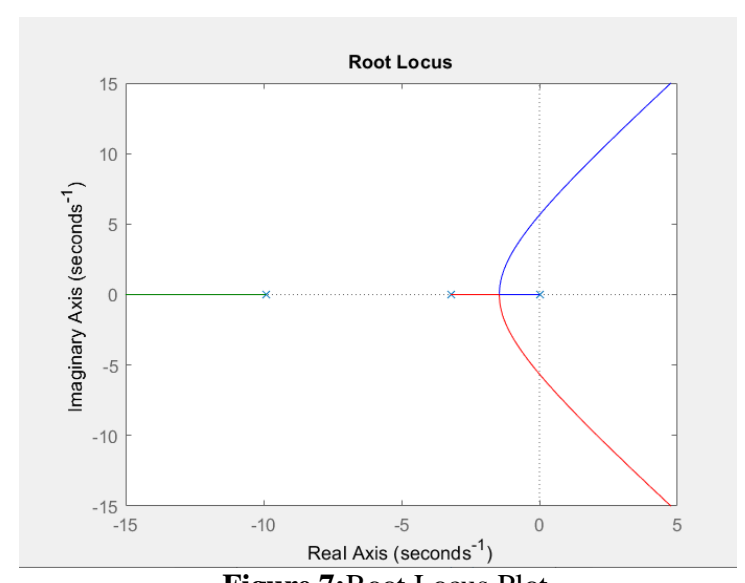

Figure 7:Root Locus Plot 


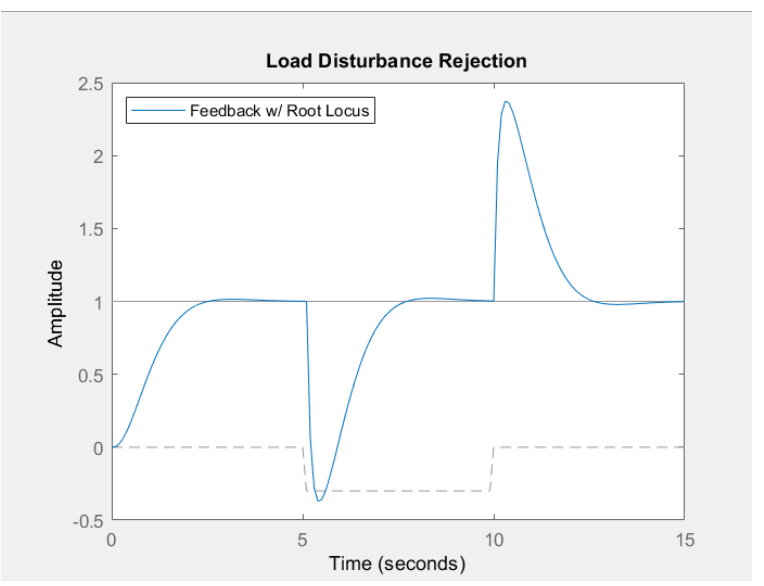

Figure 8:Feedback with root locus load disturbance rejection

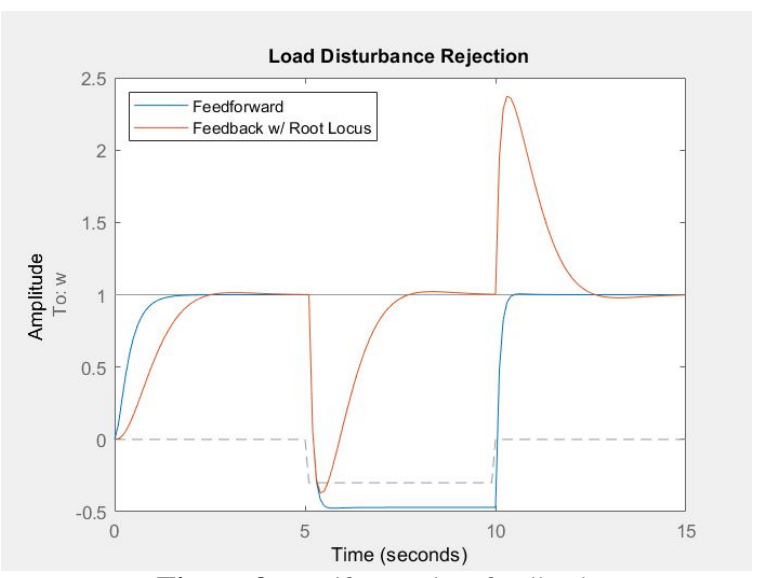

Figure 9:Feedforward vs feedback

\section{ANALYSIS OF DATA}

Figure 9 shows the step response of a DC motor based on figure 5.1. This is found using the transfer function model in the control systems toolbox in MATLAB. As seen in the figure, as the angular velocity increases as the step voltage increases until it reaches steady stateat around 1.75 seconds. The plot of the disturbance rejection of a feedforward DC motor is shown in Figure 9.1. The torque load disturbance which is also the viscous friction is at $-0.3 \mathrm{Nm}$. It is applied between $5 \mathrm{~s}$ and $10 \mathrm{~s}$ and as seen, there is a huge impact on the response. Thus, a feedforward DC control does not handle disturbances well. The next is the feedback DC control with root locus DC control method. In Figure 9.2.1, the root locus plot of the feedback DC control is shown. It is important for the $\mathrm{K}$ to be determined in order to use the root locus technique in the open-loop $1 / \mathrm{s} *$ transfer $(\mathrm{Va}->\mathrm{w})$. Based on the root locus plot, $\mathrm{k}=5$ can be considered. This gain is then tested with the same design as the feedforward system. As seen in Figure 9.2.2, the feedback with root locus technique the torque disturbance applied between $5 \mathrm{~s}$ and $10 \mathrm{~s}$ was gradually rejected. Then, the two methods, the feedforward and feedback with root locus are plotted together. The difference between the two can clearly be seen in Figure 9.3.1. Although the disturbance was not fully rejected using the feedback with the root locus method, it is better at handling disturbance than the feedforward technique who was not able to reject the disturbance all throughout the period wherein the disturbance was applied.

\section{CONCLUSION}

In conclusion, the group was able to successfully simulate and compare the feedforward and feedback control systems against each other. According to the results, the feedback control system showed better performance with respect to disturbance rejection. The more complex design of the feedback controller gave it the edge when pitted against the simpler feedforward design. The feedback loop allowed the system to utilize a steady-state error analysis which gave it better stability than the feedforward controller. However, this should not sway designers from implementing the feedback motor controller into every design. Because the simpler feedforward motor controller also has its benefits. For instance, its simpler design allows it to be easily interpreted which could also allow for better control and granular customization according to the needs of the user. Another side effect of being simple, developing and implementing the feedforward motor controller would also be more cost-efficient. As previously mentioned, there are still many applications of feedforward controllers in the industry where a continuous duty cycle is required such as basic electric fans, conveyor belts, etc. By contrast, feedback DC motor controllers have added complexity due to the feedback loop which leads to better performance. These motor controllers are recommended for systems that require a higher level of control, precision, and stability e.g. drills, robotic arms, etc.

\section{RECOMMENDATIONS}

In this paper, the researchers have concluded that the feedback control system has a better performance characteristic, compared to the feedforward control system. Although, it is practical to research and experiment on whether the combination of feedforward and feedback control systems will be more efficient compared to a single type of control, especially in a particular system's disturbance rejection. In these combination type control systems, it is recommended to use an armature voltage speed control scheme, this will grant the system the use of two distinct controllers. It will be inefficient to use proportional integral derivative controllers due to its response being highly oscillating and it is very sensitive to load disturbances and parameter variations. The recommended combined feedback and feedforward control system is a practical study because having a feedforward control can predict variations and having a feedback will ensure adjustment to these variations. Feedback control systems will have reference speed tracking and if the system will obtain inaccuracies, the feedforward can compensate and maintain the desired output ideally. It is also recommended to test whether such a system will have time delays in compensation and adjustments for the system as a whole. If such delay will occur, it is recommended that a study on the minimization or removal of these types of delay be conducted due to the fact that these delays may become critical in other 
applications.[29] It is a given that the real world and the systematic applications for control systems have many non-linearities that limit effectiveness of feedback and feedforward control schemes that is why it is also recommended to study other control systems that can replace or compensate for the inefficiencies of these systems to achieve outputs in greater performance criterias. The effectiveness of these systems will ensure great output due to the prediction of the feedforward and the compensation of the feedback.[30]

\section{REFERENCES}

[1] F. Asadi, "Comparison of Different DC Motor Modeling Techniques," Journal of Electronic Research and Application, vol. 2, no. 2, 2018.

[2] M. Gan, M. Zhang, C. Zheng, and J. Chen, "An adaptive sliding mode observer over wide speed range for sensorless control of a brushless DC motor," Control Engineering Practice, vol. 77, pp. 52-62, 2018.

[3] F. Hidayanti, H. Santoso, E. Wati and G. Prasetyo, "Design of miniature complex loop input/output simulator for fuel gas and seal gas filter separators by using distributed control system," International Journal of Emerging Trends in Engineering Research, vol. 8, no. 7, pp. 3122-3128, 2020.

[5] A. Africa, P. Arevalo, A. Publico, and M. Tan, "Time response analysis of control systems," International Journal of Emerging Trends in Engineering Research, vol. 8, no. 4, pp. 1416-1420, 2020.

[6] Z. Bitar, S. Jabi, and I. Khamis, "Modeling and Simulation of Series DC Motors in Electric Car," Energy Procedia, vol. 50, 2014.

[7] K. Lynch, N. Marchuk, and M. Elwin, "DC Motor Control," Embedded Computing and Mechatronics with the PIC32, pp. 439-458, 2016.

[8] Z. Qiu, L. Xie, and K. You, "Feedback-Feedforward Control Approach to Distributed Optimization," 2019 American Control Conference (ACC), 2019.

[9] J. Chotai and K. Narwekar, "Modelling and position control of brushed DC motor," 2017 International Conference on Advances in Computing, Communication and Control (ICAC3), 2017.

[10]A. Tun, "DC Motor Control System with PID Controller," International Journal of Science and Engineering Applications, vol. 7, no. 8, pp. 250-253, 2018.

[11] M. Taut, G. Chindris, and D. Pitica, "PID Algorithm used for DC Motor Control," 2018 IEEE 24th International Symposium for Design and Technology in Electronic Packaging (SIITME), 2018.

[12] V. Saisudha, G. Seeja, V. Radhamani Pillay, G. Manikutty, and R. Bhavani, "Analysis of speed control of DC motor using LQR method," International Journal of Control Theory and Applications, Serials Publications, vol. 9, no. 15, pp. 7377-7385, 2016.

[13] V. Yurkevich and N. Stepanov, "PWM speed control of DC motor based on singular perturbation technique," 2014 6th International Congress on Ultra-Modern
Telecommunications and Control Systems and Workshops (ICUMT), 2014.

[14]F. Ahmad, M. Pandey, and M.Zaid, "Sensorless Control of Brushless DC Motor by Zero-Crossing Detection Pulse Generation with Adaptive Power Factor Control Technique," 2018 IEEE International Conference on Environment and Electrical Engineering and 2018 IEEE Industrial and Commercial Power Systems Europe (EEEIC / I\&CPS Europe), 2018.

[15] A. Omara,M.Sleptsov, and A. Diab, "Cascaded fuzzy logic based direct torque control of interior permanent magnet synchronous motor for variable speed electric drive systems," 2018 25th International Workshop on Electric Drives: Optimization in Control of Electric Drives (IWED), 2018.

[16] M. Gaiceanu, "Optimal Control of the DC Motors with Feedforward Compensation of the Load Torque," Springer Proceedings in Energy 3rd International Congress on Energy Efficiency and Energy Related Materials (ENEFM2015), pp. 27-35, 2016.

[17] C. Huang, and Y. Bai, "Configurations and modelling of networked feedforward-feedback control systems," Proceedings of the 10th World Congress on Intelligent Control and Automation, 2012.

[18]X. Xue and K. Cheng, "An Energy-Saving Scheme of Variable Voltage Control for Three-Phase Induction Motor Drive Systems," 2006 2nd International Conference on Power Electronics Systems [27]and Applications, 2006.

[19]F. Limbong, "The use of neural network (NN) to predict voltage drop during starting of medium voltage induction motor," 2016 3rd International Conference on Information Technology, Computer, and Electrical Engineering (ICITACEE), 2016.

[20] S. T. R. and A. S. A. "Armature Voltage Control: A Modus Operandi for Speed Control of DC motor employing 1phase Full Converter Drives," 2020 5th International Conference on Communication and Electronics Systems (ICCES), 2020.

[21] Y. Xing, J. Jin, B. Du, R. Sun, X. Chen, F. Li, and Y. Zhu, "Influence of Flux Diverter on Magnetic Field Distribution for HTS Transformer Windings," IEEE Transactions on Applied Superconductivity, vol. 26, no. 7, pp. 1-5, 2016.

[22] A. Salah El Din Zein El Din, "PLC-Based Speed Control of DC Motor," 2006 CES/IEEE 5th International Power Electronics and Motion Control Conference, 2006.

[23] U. Manwong, S. Boonpiyathud, and S. Tunyasrirut, "Implementation of a dSPACE DSP-based state feedback with state observer using Matlab/Simulink for a speed control of DC motor system," 2008 International Conference on Control, Automation and Systems, 2008.

[24] W. Mitkowski, M. Zagórowska, and W.Bauer, "Comparative Analysis of DC Motor Control System," Applied Mechanics and Materials, vol. 817, pp. 111-121, 2016.

[25] A. Parastiwi, P. Al-Akbary, and H. Safitri, "Analysis and testing of DC motor control system for electric bike," 
Aaron Don M. Africa et al., International Journal of Emerging Trends in Engineering Research, 8(9), September 2020, 5586 - 5592

IOP Conference Series: Materials Science and Engineering, vol. 732, 012055, 2020.

[26] N. Khaled, B. Pattel, and A. Siddiqui, "Digital Twin Development and cloud deployment for a DC Motor Control embedded system," Digital Twin Development and Deployment on the Cloud, pp. 339-512, 2020.

[27] X. Song, B. Han, and K. Wang, "Sensorless Drive of High-Speed BLDC Motors Based on Virtual Third-Harmonic Back EMF and High-Precision Compensation," IEEE Transactions on Power Electronics, vol. 34, no. 9, pp. 8787-8796, 2019.

[28] H. Grabner, W. Amrhein, S. Silber, and K. Nenninger, "Nonlinear Feedback Control of a Bearingless Brushless DC Motor," 2005 International Conference on Power Electronics and Drives Systems, 2005.

[29] M. Belfeki, "Adaptive Output Feedback Regulation for a Class of Uncertain Feedforward Time-Delay Nonlinear Systems," Journal of Systems Science and Complexity, vol. 33, no. 3, pp. 604-621, 2020.

[30] N. Tadrist and H. Zeroug, "Development of brushless DC motor drive system for teaching purposes using various PWM control techniques for speed control," 2014 IEEE 15th Workshop on Control and Modeling for Power Electronics (COMPEL), 2014. 